Sharif University of Technology
Scientia Iranica
SCIENTIA
IRAN Transactions B: Mechanical Engineering
www.scientiairanica.com

\title{
Fatigue behavior of nano-grained pure copper processed by equal channel angular rolling
}

\author{
A. Habibi ${ }^{a}, *$, M. Ketabchi ${ }^{\mathrm{a}}$ and M. Eskandarzadeh ${ }^{\mathrm{b}}$ \\ a. Department of Mining and Metallurgical Engineering, Amirkabir University of Technology, Tehran, Iran. \\ b. Department of Mechanical Engineering, Kharazmi University, Tehran, Iran. \\ Received 6 June 2015; received in revised form 8 March 2016; accepted 30 May 2016
}

\author{
KEYWORDS \\ Nano-grained copper; \\ Severe plastic \\ deformation; \\ Equal channel angular \\ rolling; \\ fatigue.
}

\begin{abstract}
The equal channel angular rolling process was successfully performed on commercial pure copper. After 4 passes of this process, grains with a diameter of about 70-500 $\mathrm{nm}$ were formed. The fatigue test results showed that the ultra-fine grained copper represents a longer lifetime under stress-controlled fatigue. To clarify the formation process of surface damage, morphological changes in the fractured surface were monitored by scanning electron microscopy.
\end{abstract}

(C) 2017 Sharif University of Technology. All rights reserved.

\section{Introduction}

The development of Severe Plastic Deformation (SPD) processes for investigating the structural evolution has received considerable attention over the past decades [1]. Various SPD techniques have been applied to generate the high strains required to produce bulk UFG materials. Among these techniques, the Equal Channel Angular Pressing (ECAP) process has proved attractive. In this process, strain-induced grain refinement can be resulted by passing the workpiece into the die equipped with two equal channels with the same cross-sectional area which are intersected at a certain angle [2]. The method of Equal Channel Angular Rolling (ECAR), which is based on ECAP, provides repeated shear deformation on strip metals through dissimilar channels and feeding roll $[3,4]$.

Grain size is a principal structural factor affecting the mechanical properties and fatigue behavior of metals [5].The fatigue life is affected by the required times for crack nucleation and propagation. The resistance to crack initiation increases with higher strength while

\footnotetext{
*. Corresponding author. Tel.: +98 2164542966 ;

Fax: +982166405846

E-mail address: a_habibi@aut.ac.ir (A. Habibi)
}

resistance to crack propagation requires ductility. A combination of high strength and good ductility in the nanostructured materials enhances their fatigue properties $[2,6]$. Several studies have explored the grainsize effects on cyclic deformation of Ultra-Fine Grain (UFG) materials produced by ECAP. Most of them have shown an enhanced fatigue life of the UFG copper than the coarse-grained counterpart when the cycling is stress-controlled [7-9], while grain refinement under plastic strain-controlled testing is not advantageous to both high [10,11] and low purity coppers [8] due to cyclic softening under strain-controlled fatigue. Also, it is shown that a decrease in the purity of copper can improve the fatigue strength at $\mathrm{S}-\mathrm{N}$ curve [12].

In this study, nanostructured pure copper was fabricated by the ECAR process and mainly focused on the effect of the ECAR process on the fatigue behavior of the pure copper sheet.

\section{Materials and methods}

A set of copper properties and dimensions similar to that reported in [13] was used to prepare the ECARed copper. The ECAR device used in this study is illustrated in Figure 1. Copper samples were subject to the ECAR process for 4 passes in route C. Microhardness 


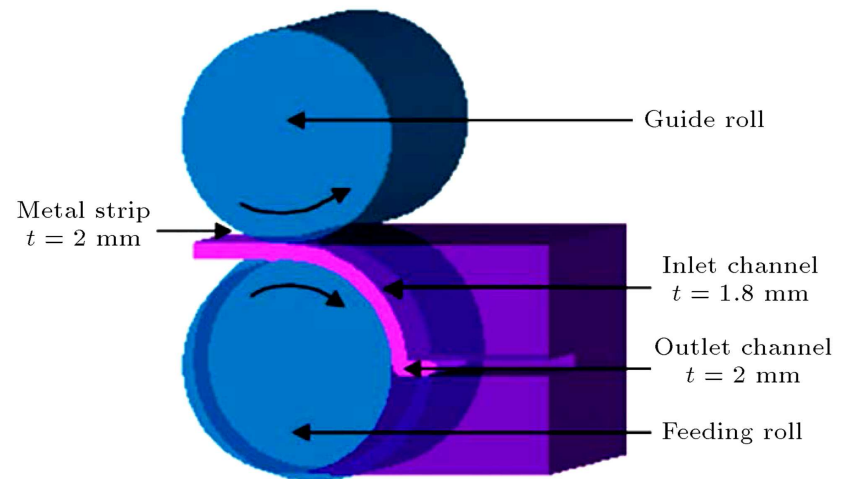

Figure 1. Schematic of the ECAR device.

variations were measured by a Vickers hardness tester with a pyramidal diamond indenter subject to a $25 \mathrm{~g}$ load at the side surface of the specimens. Samples were also prepared For Scanning Electron Microscopy (SEM) and Atomic Force Microscopy (AFM) by mechanical grinding and etching with 50 pct nitric acid.

The room temperature tensile test was conducted on plate-type specimens machined along the ECAR die direction at a strain rate of $2.1 \times 10^{-3} \mathrm{~s}^{-1}$ by an Instron 8502 testing machine. The gauge length and width of the tensile specimens were 25 and $6 \mathrm{~mm}$, respectively (based on ASTM standard E8-00b). For the study of fatigue of ECARed copper, the relationship between the applied stress and cyclic number to the failure (the $\mathrm{S}-\mathrm{N}$ relation) was examined at room temperature by an Instron 8502 testing machine. The fatigue test was conducted under symmetrical loading conditions ( $R=-1$, where $R$ is the ratio of the minimum stress to maximum stress for a cycle stress) at a loading frequency of $3.5 \mathrm{~Hz}$. Dog-bone shaped samples for the fatigue test samples were cut with a gauge section of $10 \mathrm{~mm}$ in length and $4 \mathrm{~mm}$ in width according to the ASTM standard E466-96. The axes of the flat samples were parallel to the rolling direction. Scanning electron microscopy was employed for observation of surface morphologies after fatigue fracture.

\section{Results and discussions}

\subsection{Microstructure}

The scanning electron microscopic micrograph (Figure 2(a)), atomic force microscopic micrograph (Figure 2(b)), and grain-size profile (Figure 2(c)) from side surface of the 4-pass ECARed specimen show sub-grain sizes of $70-500 \mathrm{~nm}$. The grains produced by the 4 passes of the ECAR process are characterized by irregular, slightly elongated shape, and oriented structure. Also, the SEM image of ECARed specimen shows formation of copper particles in microstructure.

Induction of severe shear deformation to materials

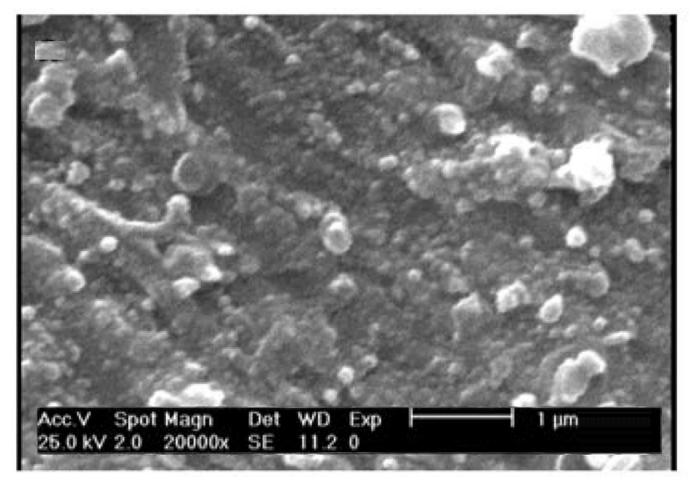

(a)

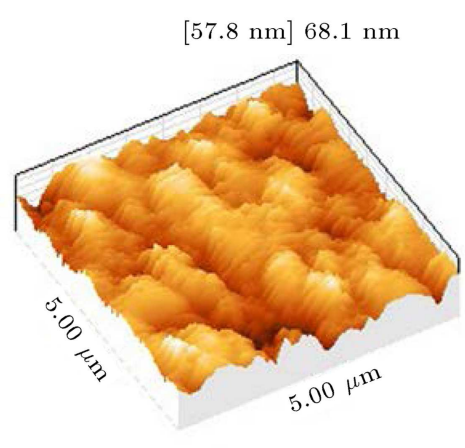

(b)

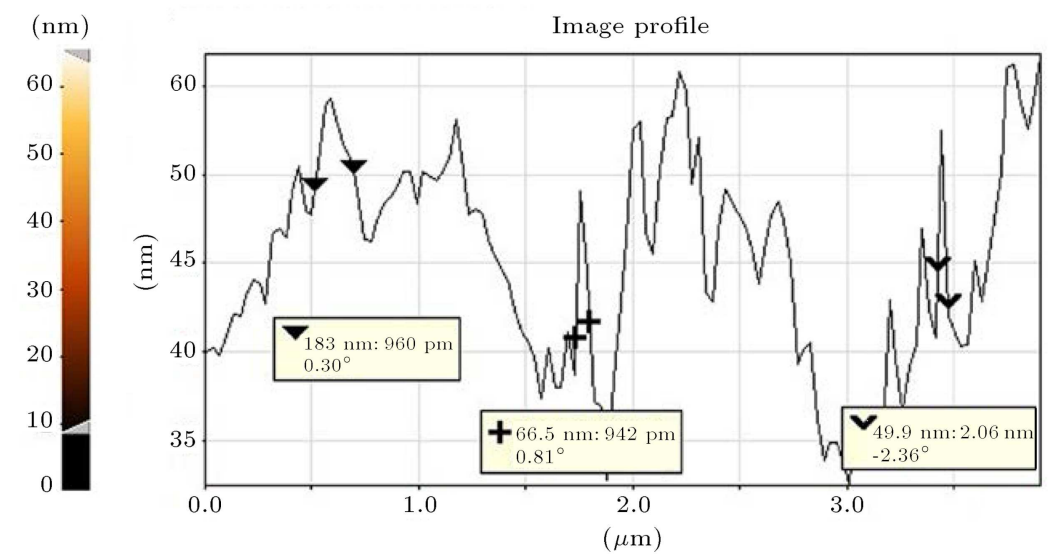

(c)

Figure 2. (a) SEM. (b) AFM micrographs. (c) Grain-size profile of 4-pass ECARed copper. 
Table 1. Mechanical properties of as-annealed, 1- and 4-pass ECARed pure copper.

\begin{tabular}{ccccc}
\hline $\begin{array}{c}\text { Pass } \\
\text { number }\end{array}$ & $\begin{array}{c}\text { Yeild strength } \\
(\mathbf{M P a})\end{array}$ & $\begin{array}{c}\text { Ultimate tensile } \\
\text { strength }(\mathbf{M P a})\end{array}$ & $\begin{array}{c}\text { Elongation } \\
(\mathbf{\%})\end{array}$ & $\begin{array}{c}\text { Microhardness } \\
(\mathbf{H V})\end{array}$ \\
\hline As-annealed & 109 & 228 & 38 & 60 \\
1-pass ECAR & 199 & 242 & 30 & 85 \\
4-pass ECAR & 278 & 288 & 12 & 103 \\
\hline
\end{tabular}

by passing them through a die with two intersected channels plays a critical role in the plastic straininduced grain refinement processes and in the minimum grain size obtainable via plastic deformation [14]. The effect of the ECAR process on microstructure of the $\mathrm{Cu}$ has been previously studied [13].

\subsection{Microhardness and tensile test results}

The results of tensile tests are shown in Table 1 in which measured values of yield strength, ultimate tensile strength, elongation and microhardness of asannealed, and 1- and 4-pass ECARed specimens are listed. These results show a noticeable increase of strength and microhardness as a function of a number of ECAR passes. At the same time, the maximum elongation is the lowest for the samples after 4 passes. After the first pass, the yield strength significantly increased about $85 \%$ while continuing the ECAR process up to 4 passes shows only an $80 \%$ increase. The tensile strength did not experience much variation. The ECAR process causes significant reduction of elongation after 4 passes. It also shows an increase (70\%) in microhardness after 4 passes. Previous work [13] showed that the mechanical properties did not change significantly by increasing the number of passes to more than three passes.

The effect of the ECAR process on microhardness magnitude and strength of copper has been previously studied [13] and can be summarized as follows. The increase of the strength of nanostructured copper might be due to some reasons. Firstly, the effect of grain size on strength generally follows the Hall-Petch relation and any variation of grain size leads to a significant change in yield strength of bulky materials. Secondly, a large value of plastic deformation can occur in samples by the ECAR process. The strain hardening or dislocation strengthening plays a main role in the strength increase. Decreased elongation can also be justified by strain hardening. The rapid increase of microhardness seems to be attributed to strain hardening as a result of sub-grain boundaries formation rather than grain refinement [15].

\subsection{Fatigue properties enhancement}

S-N curves for both as-annealed and 4-pass ECARed pure coppers are shown in Figure 3. In this figure, the data are compared with the earlier studies of Goto et al. [7] and $\mathrm{Xu}$ et al. [8] on ultra-fine grained

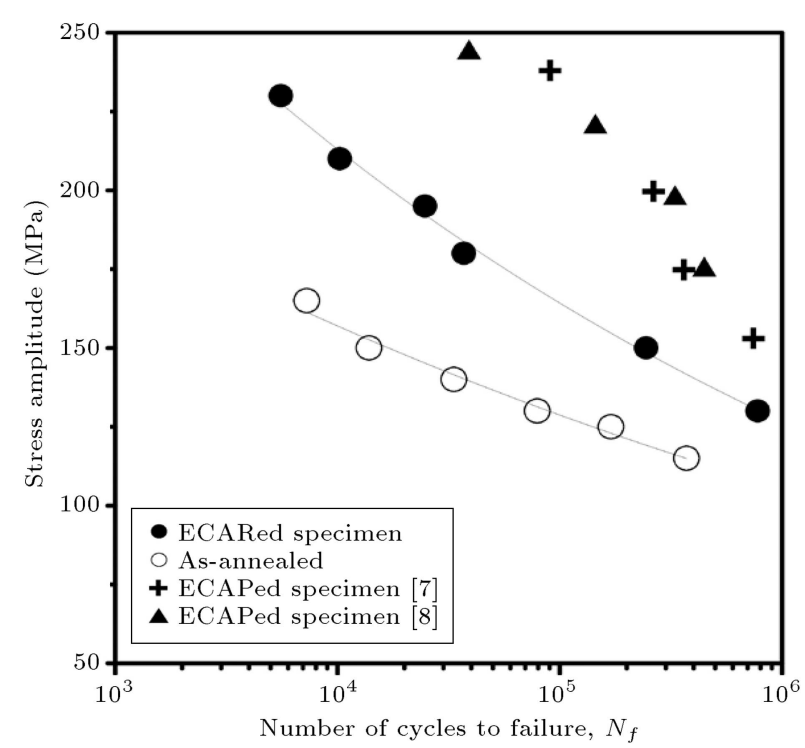

Figure 3. S-N curves of as-annealed and 4-pass ECARed copper compared with ECAPed copper of earlier work.

$\mathrm{Cu}$. The number of cycles to the fracture increased with a decrease in stress amplitude. The ECARed copper specimen shows enhancement in fatigue life under stress-controlled testing for all stress amplitudes. The degree of enhancement increases with an increase in stress amplitude. This means that nanostructured copper shows more enhancements in fatigue life in the higher stress amplitude, which is related to grain refinement. On the other hand, in excess of $N=10^{6}$ cycles, the fatigue life of ECARed copper tends to coincide with that of as-annealed copper. Experimental data show that the fatigue limit, as well as the yield strength, follows the standard Hall-Petch relationship [16]. The differences between ECARed and ECAPed samples in Figure 3 can be related to details of these processes. The UFG microstructure of copper can contain equiaxed or elongated grains. The elongated structure of ECARed sample can accelerate shear banding and cyclic softening processes and significantly reduce its fatigue life in comparison to equiaxed structure of ECAPed specimens [10]. Also, the higher tensile properties of the ECAPed samples (yield strength of about $400 \mathrm{MPa}$ and ultimate tensile strength of about $430 \mathrm{MPa}$ ) can be another reason for this fatigue life enhancement.

The fatigue limits on $\sim 5 \times 10^{6}$ cycles are 135 and $110 \mathrm{MPa}$ for ECARed and as-annealed coppers, 
respectively. These magnitudes show an enhancement of about $25 \%$ in fatigue properties of 4 -pass ECARed pure copper. This shows a slight difference in fatigue limit stress between as-annealed and ECARed coppers, even though the yield strength of ECARed copper is about 1.5 times larger than the annealed one.

Researchers have shown that the grain refinement results in a greater resistance to crack initiation and faster crack propagation [17,18] [Cavaliere, 2009 \#465]. Higher strength and microhardness in ultra-fine and nanostructured grained metals, especially near the surface regions which are crack nucleation sites, cause greater resistance to crack initiation by prevention of plastic deformation at the beginning of fatigue testing. This process increases the incubation period for crack nucleation and the total fatigue life of ECARed copper at high stresses [6,17]. The dislocation density within the grains could increase after the ECAR process. The dislocation interaction with the other dislocations and grain boundaries play an important role in the fatigue resistance of pure UFG copper [5]. The absorption of defects and mobile dislocations inside the grains determines the fatigue life of ECARed copper [7]. The previous research studies have presented that the fatigue test of UFG copper at high stress amplitudes leads to cyclic softening and grain coarsening. The slip bands formation inside coarse grains provides suitable sites for the crack initiation. Therefore, the differences in fatigue lifetime of ECARed sample and as-annealed copper resulted from different crack initiation lifetimes. On the other hand, cyclic hardening and weak grain coarsening can occur under low stress amplitudes [8,12]. Therefore, longer time of cyclic softening and grain coarsening at the UFG structures, which increases the incubation period for crack nucleation, is the main responsible mechanisms for enhancement of fatigue lifetime under stress-controlled fatigue test.

The result of experiment shows ultra-fine grained copper exhibiting a prominent rise in their fatigue performance at high-stress amplitudes by increasing the recovery time (dynamic recovery mechanisms which lead to annihilation of dislocations). Thus, in a highstress amplitude, strength is dominant and improves the material's resistance to crack initiation, whereas in a strain-controlled test, ductility determines the number of cycles to fracture controlled by crack propagation $[5,6]$. Then, it was suggested that by producing bi-modal grain structures with small and large grains, a combination of strength and ductility and improved fatigue properties may be achieved.

\subsection{Fractography}

To study characteristics of crack growth, SEM observations of the fracture surfaces were made on ECARed copper at high (230 MPa) and low (150 MPa) stress amplitudes (Figure 4). Figure 4(a) shows a whole macroscopic view of the fractured surface. Both surfaces confirm low plastic deformation and moderately ductile fracture. Comparison between two samples at 150 and $230 \mathrm{MPa}$ (Figure 4(a)) shows a small plastic deformation in the $150 \mathrm{MPa}$ sample. The increased stress in the fatigue test causes transformation of ductile to moderately ductile fracture in the samples.

The first step in the fatigue process is softening or hardening. Previous research showed that softening and hardening happen for materials with $\frac{\sigma_{u t s}}{\sigma_{y}} \prec 1.2$ and $\frac{\sigma_{u t s}}{\sigma_{y}} \succ 1.4$, respectively [19]. This ratio is about 1.04 for 4-pass ECARed copper which confirms softening as the first step of fatigue.

The fatigue fractured surface shows three regions: crack nucleation, crack propagation, and final fracture. As seen in Figure 4(b), (c), and (d), three fracture regions were observed. The first region (Figure 4(b)) is related to crack initiation and minor crack growth, in which a short crack is generated by the sliding of grain boundaries. The flat fracture surface is formed by grain boundaries sliding [20]. The white arrows in Figure 4(b) show multiple initiation cracks at $230 \mathrm{MPa}$ and $150 \mathrm{MPa}$. In fact, increase in stress amplitudes will activate more nucleation sites. Higher stress amplitudes induce an earlier transition with a shorter crack length. In the second region (Figure 4(c)) which is considered as crack propagation, the morphological features of the fracture surface change as a granulated surface. Deeper and smaller dimples are of characteristics of this region. This is approximately the same for both stress amplitudes. In the last region (Figure 4(d)), the fracture surface is dominated by the oriented dimple. This region is related to the final fracture of the specimen and fatigue crack propagates in the direction perpendicular to the process direction. The SEM image of lower stress (Figure 4(d)) shows more oriented dimples in this region. As a result, there is no essential difference in transition of the morphological features of the fracture surface at low and high stress amplitudes [21].

\section{Conclusion}

Commercial pure copper was processed by the equal channel angular rolling process. The following conclusions are drawn:

- Nano-grained pure copper was obtained by the ECAR process. The grain size was measured using SEM and AFM micrographs, and it was about 70$500 \mathrm{~nm}$ after 4 passes;

- The microhardness magnitude of the ECARed pure copper is $70 \%$ higher than the un-ECARed one;

- The results of the tensile test showed improvements of more than 1.5 times the yield strength and $25 \%$ in the ultimate tensile strength after 4 passes of 
$150 \mathrm{MPa}$

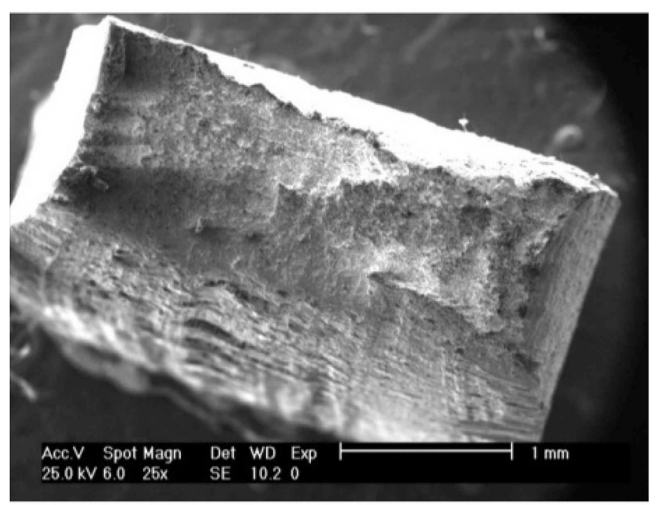

(a) Fractured surface
$230 \mathrm{MPa}$
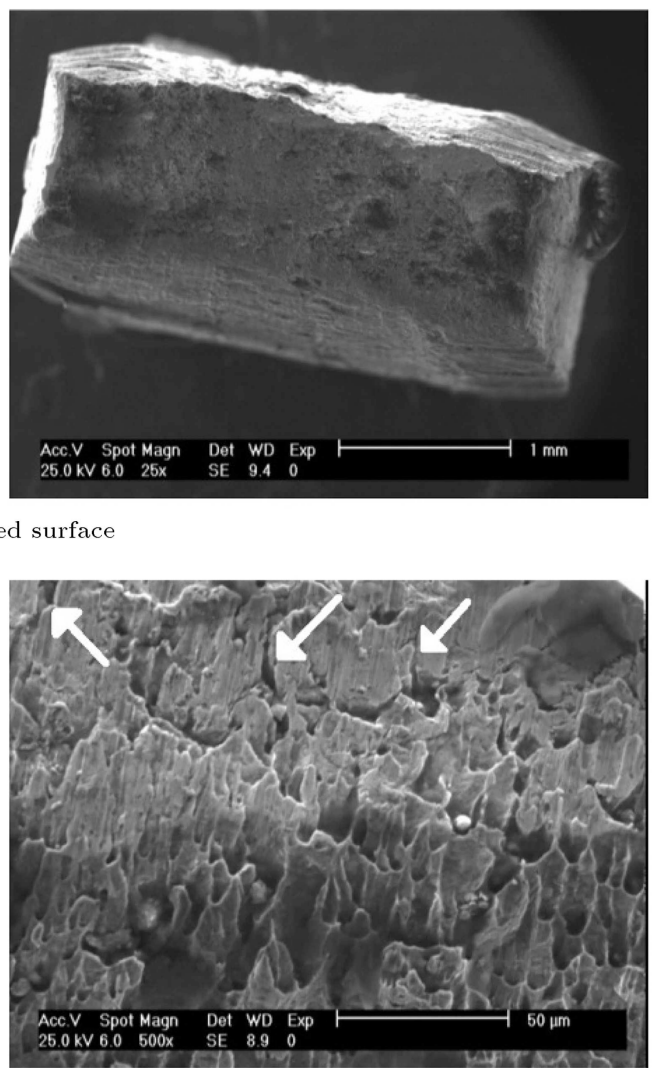

(b) Region 1
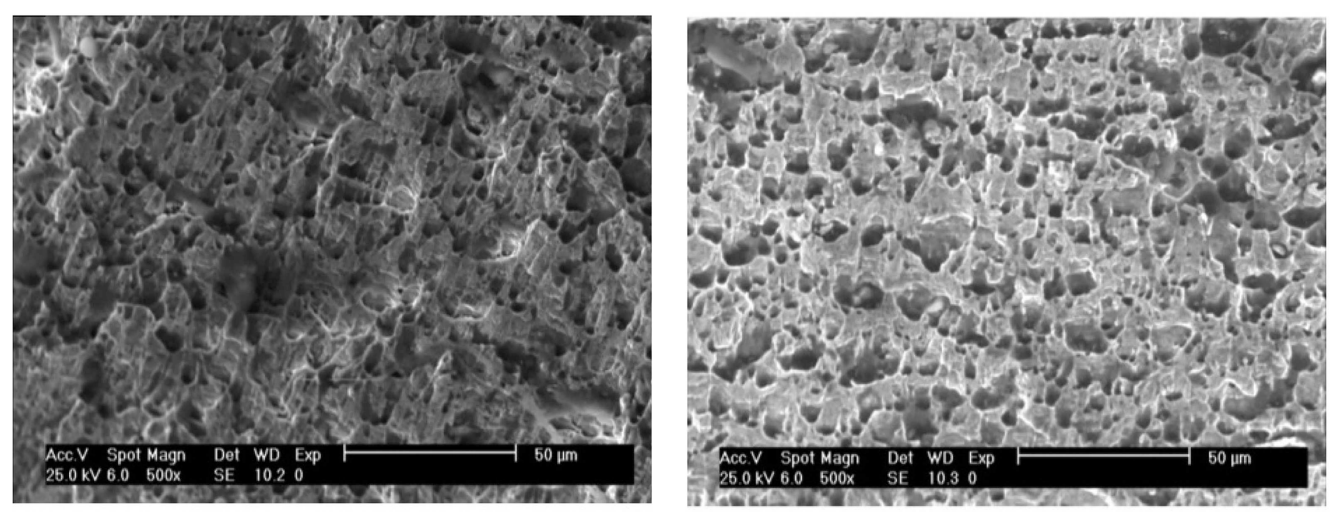

(c) Region 2
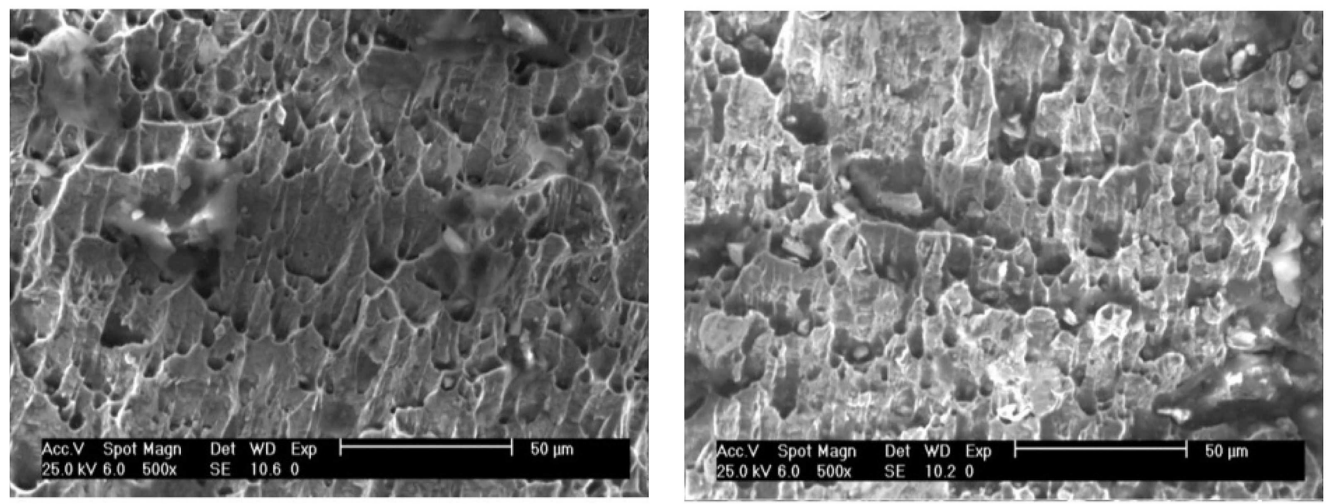

(d) Region 3

Figure 4. SEM micrographs of 4-pass ECARed copper fracture surfaces in 150 and $230 \mathrm{MPa}$ stresses. 
ECAR in comparison to as-annealed copper. The elongation of the alloys falls about $68 \%$ during the ECAR process;

- The result of S-N curve shows an increase in fatigue strength of the ECARed copper compared to the as-annealed sample. This was due to the improved mechanical properties and the greater resistance to crack initiation.

\section{References}

1. Li, J., Li, F., Zhao, C., Chen, H., Ma, X. and Li, J. "Experimental study on pure copper subjected to different severe plastic deformation modes", Mater. Sci. Eng. A, 656, pp. 142-150 (2016).

2. Valiev, R.Z. and Langdon, T.G. "Principles of equalchannel angular pressing as a processing tool for grain refinement", Prog. Mater. Sci., 51(7), pp. 881-981 (2006).

3. Lee, J.C., Shu, J.Y. and Ahn, J.P. "Work-softening behavior of the ultrafine-grained $\mathrm{Al}$ alloy processed by high-strain-rate, dissimilar-channel angular pressing", Metal. Mater.Trans. A, 34(3), pp. 625-632 (2003).

4. Chung, Y.H., woo Park, J. and Lee, K.H. "An analysis of accumulated deformation in the equal channel angular rolling (ECAR) process", Metal. Mater. Int., 12(4), pp. 289-292 (2006).

5. Estrin, Y. and Vinogradov, A. "Fatigue behaviour of light alloys with ultrafine grain structure produced by severe plastic deformation: an overview", Int. J. Fatigue, 32(6), pp. 898-907 (2010).

6. Djavanroodi, F., Ebrahimi, M., Rajabifar, B. and Akramizadeh, S. "Fatigue design factors for ECAPed materials", Mater. Sci. Engi. A, 528(2), pp. 745-750 (2010).

7. Goto, M., Han, S., Kitamura, J., et al. "S-N plots and related phenomena of ultrafine grained copper with different stages of microstructural evolution", Int. J. Fatigue, 73, pp. 98-109 (2015).

8. Xu, C., Wang, Q., Zheng, M., et al. "Fatigue behavior and damage characteristic of ultra-fine grain low-purity copper processed by equal-channel angular pressing (ECAP)", Mater. Sci. Eng. A, 475(1), pp. 249-256 (2008).

9. Kunz, L., Mechanical Properties of Copper Processed by Severe Plastic Deformation, INTECH Open Access Publisher (2012).

10. Mughrabi, H., Höppel, H. and Kautz, M. "Fatigue and microstructure of ultrafine-grained metals produced by severe plastic deformation", Scripta Mater., 51(8), pp. 807-812 (2004).

11. Agnew, S. and Weertman, J. "Cyclic softening of ultrafine grain copper", Mater. Sci. Eng. A, 244(2), pp. 145-153 (1998).

12. Goto, M., Han, S., Yakushiji, T., Kim, S. and Lim, C. "Fatigue strength and formation behavior of surface damage in ultrafine grained copper with different nonequilibrium microstructures", Int. J. Fatigue, 30(8), pp. 1333-1344 (2008).

13. Habibi, A., Ketabchi, M. and Eskandarzadeh, M. "Nano-grained pure copper with high-strength and high-conductivity produced by equal channel angular rolling process", J. Mater. Process. Technol., 211(6), pp. 1085-1090 (2011).

14. Wang, K., Tao, N., Liu, G., Lu, J. and Lu, K. "Plastic strain-induced grain refinement at the nanometer scale in copper", Acta Mater., 54(19), pp. 5281-5291 (2006).

15. Hosseini S.A. and Manesh, H.D. "High-strength, highconductivity ultra-fine grains commercial pure copper produced by ARB process", Mater. Design, 30(8), pp. 2911-2918 (2009).

16. Thompson, A.W. and Backofen, W. "The effect of grain size on fatigue", Acta Metall., 19(7), pp. 597606 (1971).

17. Hanlon, T., Tabachnikova, E. and Suresh, S. "Fatigue behavior of nanocrystalline metals and alloys", Int. J. Fatigue, 27(10), pp. 1147-1158 (2005).

18. Cavaliere, P. "Fatigue properties and crack behavior of ultra-fine and nanocrystalline pure metals", Int. J. Fatigue, 31(10), pp. 1476-1489 (2009).

19. Hertzberg, R.W., Deformation and Fracture Mechanics of Engineering Materials, John Wiley \& Sons, p. 697 (1983).

20. Okayasu, M., Sato, K., Mizuno, M., Hwang, D. and Shin, D. "Fatigue properties of ultra-fine grained dual phase ferrite/martensite low carbon steel", Int. J. Fatigue, 30(8), pp. 1358-1365 (2008).

21. Goto, M., Ando, Y., Han, S., Kim, S., Kawagoishi, N. and Euh, K. "The effect of microstructural inhomogeneity on the growth paths of surface-cracks in copper processed by equal channel angular pressing", Eng. Fract. Mech., 77(11), pp. 1914-1925 (2010).

\section{Biographies}

Asiyeh Habibi is currently a PhD student in Material Engineering in Amirkabir University of Technology. She received her MSc degree from Amirkabir University in 2013, where her thesis work consists of severe plastic deformation.

Mostafa Ketabchi is an Associate Professor in Amirkabir University of Technology. He obtained his $\mathrm{PhD}$ degree from Tohoko University (1999). His research interests are mainly mechanical metallurgy, especially severe plastic deformation.

Mohammad Eskandarzadeh is currently an MSc student in Mechanical Engineering in Kharazmi University of Tehran. His interests are mechanical properties of nano-materials and composites. 